\title{
Glass Structures \& Engineering, Themed Issue: Challenging Glass
}

\author{
J. Belis 1 C. Louter • J. H. Nielsen • \\ M. Overend · J. Schneider
}

Published online: 24 May 2016

(C) Springer International Publishing Switzerland 2016

It is our great pleasure to present the very first issue of Glass Structures \& Engineering, themed "Challenging Glass". Twenty outstanding papers have been selected following a strict double-blind peer review process by top experts in the field. The papers focus on challenging glass solutions and present novel findings in several structural glass subdomains, such as hybrid glass solutions, glass strength and stability, adhesive connections, insulating glass units, glass under blast loading, and projects \& case-studies.

The structural use of glass is a young and fascinating field, characterized by recent developments in science

\section{J. Belis $(\varangle)$}

Ghent University, Ghent, Belgium

e-mail: Jan.Belis@UGent.be

J. Belis

Eindhoven University of Technology, Eindhoven,

The Netherlands

\section{Louter}

Delft University of Technology, Delft, The Netherlands e-mail: Christian.Louter@TUDelft.nl

\section{J. H. Nielsen}

Technical University of Denmark, Lyngby, Denmark e-mail: jhn@byg.dtu.dk

\section{Overend}

University of Cambridge, Cambridge, UK

e-mail:mo318@cam.ac.uk

\section{J. Schneider}

Technical University of Darmstadt, Darmstadt, Germany

e-mail: schneider@ismd.tu-darmstadt.de and technology and by rapid evolution within the building practice. The establishment of this international Glass Structures \& Engineering journal is a strong token of the significance the domain has gained over the past years, and we hope it will be a great impulse for the structural glass community. Glass Structures \& Engineering provides an international forum for presentation and discussion of developments in structural glass research and their practical applications, offering a holistic approach to research, construction and engineering. It presents research papers, review papers, technical notes, discussions, case studies and letters. As such, the journal aims to appeal to both academics and practitioners.

Glass Structures \& Engineering endeavors to become the leading platform, informing and connecting academics, designers and manufacturers on and around the latest achievements in this domain. In addition, we aim to secure an impact factor as soon as possible, as this has become an essential indicator of highly recognized scientific work. This can only be achieved with your continued support - by submitting and reviewing high quality papers and by citing them elsewhere.

We would like to express our deepest appreciation to Springer Nature-Nathalie Jacobs, Anneke Pot, Catherine Murphy and Divya Nagarajan in particularand all editorial board members who have helped to start this journal: Claudio Amadio, Paulo Cruz, Martina Eliasova, Qian Jin, Reijo Karvinen, John Kooymans, Stephen Morse, Jürgen Neugebauer, James 
O'Callaghan, Frank Wellershoff and Jian Yang. Also, we would like to gratefully acknowledge guest editor Freek Bos for his expert input in the paper selection process for this themed issue. Finally, we would like to sincerely thank our authors and reviewers for their support in achieving these goals, which will be for the benefit of the whole structural glass community.

Editors-in-Chief, June 2016 